\title{
POSITIONING IN PERSONAL GAMES: PERSPECTIVES OF THE AUTHOR- PLAYER PERSONA IN MEMOIR EN CODE: REISSUE
}

\author{
THRYN HENDERSON UNIVERSITY OF YORK
}

\begin{abstract}
In creating autobiographical narratives through games, there exists a new theoretical problem in the game-player tension: how may a game creator relate their own story through a medium that relies primarily on another (the player) to execute? The blurring and shifting lines between the game creator and player resemble the same death knell Roland Barthes sounds for the literary Author in "La mort de l'auteur" (1967). This paper proposes a more nuanced theory for understanding the 'player positioning' of autobiographical games with a triangulated framework. The player position is a player/author persona collaboration that facilitates a shared presence in the game space through various ratios of three positions: the player as the protagonist, protagonist-proxy, and witness. Through a close reading of the autobiographical game Memoir En Code: Reissue by Alex Camilleri, the paper explores how the player may perceive the autobiographical game. Viewed through the protagonist, protagonist-proxy, and witness lens, the paper interrogates how the player position alters the nature of player-author identity within the game. It offers an approach for considering how the different perspectives of the author-player persona offer meaningful game(play), and argues for the shifting presentation of the author-player persona as an effective negotiation of a shared experience in the design of autobiographical games.
\end{abstract}

\section{KEY WORDS}

Autobiographical Games; Player Positioning; Perspective; Narrative Agency

\section{INTRODUCTION}

The more you play the more you know me - Alex Camilleri, Memoir En Code (2016a)

The embodied digital self in games is often examined primarily through the lens of character or avatar (Roine 2015; Waggoner 2009; Wilde 2018). An in-game persona occurs where play involves performing a specific version of someone within the game space. However, in the game space of the autobiographical game, players play under the expectation of understanding someone who exists for them primarily through their presence within the game. Where an ingame identity is neither crafted for nor evolved from the player, neither character nor avatar is applicable as a basis for player persona-I am aware that I am not playing as myself, but I also lack the full context to play as the person acknowledged to be core to the autobiographical work. 
The player experiences a conflict of identity because they cannot claim to be the subject of the autobiography (its author).

In her exploration of autobiography as a narrative of transformation, Carolyn Barros (1998, p. 6) neatly sums up a core conceit of autobiography, arguing that "the something happened of autobiography always has reference to a $m e$ ". In autobiographical works, players are attempting to connect the narrative (the 'something happened') to the 'me' it happened to. In autobiographical game spaces, however, something is happening to or around the player through their interactions with the autobiography. In his work Phenomenology of perception, MerleauPonty (1962) argues that our continuous sensorial perception of the world, both situated and subjective, provides us with our meaningful knowledge of it. An "objective view" of a given reality, he suggests, could be obtained only by combining the views from different perspectives into a meaningful composite of depth and dimensions. My understanding of the author as an experience then can be seen as a collage of my various perspectives on the something that has happened, and the me to whom the something relates, although the "objective" possibilities of any autobiography are debatable.

In considering the player's understanding of the author as the meaningful act of play, I concern myself primarily with the player's cognitive and somatic embodiment of the game as an experience or perspective of the author (that is, the game's creator and the subject of its autobiography). The 'player position' then, is the perspective from which players understand the game, and it becomes the player's perspective(s) of the author's experiences. The way the player perceives the something happened/is happening is both situated outside of the game while the player is bodily interacting with it, and within the game through the audio/visual contexts and views that the game world provides them. The 'me' of the autobiographical game becomes a shared, mutable construct unique to each instance of play.

This paper aims to investigate the negotiation of player-author persona in autobiographical games, primarily through a close reading of Memoir En Code: Reissue (Camilleri 2016a) a vignette compilation game. This reading explores the inconsistency of the playerauthor persona in play, and examines how shifting perspectives and possibilities presented to players inform the relationship with the autobiographical content of the author. The focus is $M E C: R$ 's varied player positioning and abstracted autobiography; I argue that, to the extent that any meaningful interpretation of the content is achievable, understanding the game is a collaborative work of play which relies on an abstract and malleable persona. Each avenue of this close reading is presented in parallel with short comparative examples of smaller autobiographical vignettes, cross-examining the genre through the same analytic lens. The core aspects of this analysis centre on a triangulated conceptual framework of 'player positioning' which considers the degree to which the player assumes a protagonist, protagonist-proxy or witness role in relation to the game's events and the author's experiences.

Player positioning is shaped by the player's awareness of their character in the game, their presence in the scene, and the narrative contexts provided to them by the author. The autobiographical game, as a space between diegetic and mimetic play, is where the personal experience of the author is told and relived by the player asynchronously. By applying the player positioning framework, I offer ideas as to how the author-player persona exists as variations of protagonist, protagonist proxy and witness through the 'conversation' of play. This paper will first review the criteria through which MEC: $R$ fits the autobiographical game genre and the invitations it extends to players to understand the author through its play. It will consider the unconventional frame of presentation through which the game builds connections between author and player. I will then examine $M E C: R$ through the triangulated player positioning 
framework, alongside select other autobiographical games, to consider the influence of the shifting player perspective on the player-author persona and the act of understanding the game's autobiographical experiences.

\section{Memoir En Code: an autobiographical game}

Memoir En Code: Reissue (hereafter "MEC:R") is a self-proclaimed autobiographical game by Alex Camilleri, who describes it as "the most personal game I've ever made" (Camilleri 2016b). The game comprises a series of individual scenes about Camilleri's life, which lead the player through a variety of his lived experiences: "from the struggle of keeping together a long-distance relationship to the exploration of childhood memories" (Camilleri 2016c). After the initial release in 2015, the game was updated to include an extra scene, redeveloped graphics and audio, and a set of developer's notes on each game that aimed to provide "a new take on some recentlife[sic] events" and republished as Memoir En Code: Reissue in 2016. The game is an autobiographical character study and an experimental work, exploring the limits of game creation as a life writing tool. From graphics made from photographs of the author's hair to sections of code written using personally significant dates, Camilleri's work utilises the game beyond the playable portions to craft the digital object as a whole into an autobiographical self.

The game was chosen for this close reading due to its presentation: it is composed of multiple short vignettes collated into one larger single game, akin to a music album. This "game album" approach offers various autobiographical vignettes for close reading, all created within the same context, but utilising different techniques of player positioning. $M E C: R$ specifically was chosen over its original version because of the author's choice to extend the re-issue into a more updated self-portrayal. The core of the game is presented through nine individual vignette game "tracks". Each track is presented as a small 2D space of minimal, flat colour graphics and limited player interactions, with the exception of one purely text-based screen. The tracks can be played in order or skipped/replayed if desired; each scene is designed around a specific, contextless memory or mood of the author. While $M E C: R$ has no singular, formal narrative arc, it does prioritise an evocative sense of narrative in its framing, and players are encouraged to know Camilleri through their actions and involvement. In its first moments, before play begins, MEC:R explicitly invites the player into Camilleri's life via the message "the more you play the more you know me", framing the game that follows as an intimate personal and private investigation.

\section{IDENTITY IN AUTOBIOGRAPHICAL GAMES}

Conventionally, playing role-playing or narrative games involves an avatar (a self-representation or proxy of the player) or a character (a fully or partially realised separate entity, controlled by the character) that players might identify with or as (Shaw 2011). Players may use what they know about their in-game avatar or character to influence their behaviour, or help them to make sense of their actions: how I see the world through the camera may help me locate where I am, for example, and to ascertain my physical and emotional distance from the actions that take place therein. Within role-playing games that use an in-game avatar, I may take guidance for my actions or my in-game personality from the physical traits I have been assigned or chosen (Yee \& Bailenson 2007). Differing viewpoints, such as first-person and third-person game cameras, may imply and impact my 'game body'. The screen or camera which follows/inhabits a game character functions as a perceptive organ of a "game body", confirming its corporeal presence within the game to the player (Crick 2011): the way I gaze upon myself or the world through my eyes or the camera lends some further indication of how I am placed within the physicality of the game world, as well as the immediacy of my connection to the character. 
Many autobiographical games do not typically offer either to the player; however, I may still gain some sense of my identity from my presence as a physical entity in the game world. Werning (2017) argues that autobiographical games present author personas not as narrative character archetypes, but as sets of characteristic actions or possibilities for actions; the persona is a space for projections of players' assumptions as well as authors' personal experiences. In this possibility space, shaped by the author, players find themselves somewhere between a mimetic and diegetic player, between their narrative agency and their own desires, and acting not as a narrative transforming story protagonist, but a protagonist of the experience (Wood 2017).

Alongside issues of physicality in the game-space, autobiographical games must also consider how an avatar or character that connects players to a game space may also break them from it, such as when possible actions and intentions do not line up to player desires and expectations. An avatar asserting their own "individuality", where previously intra-dependence seemed cohesive, may lead players to seek control over them (Wilde 2018). This becomes a source of potential conflict when the desires of the player may conflict not just with that of a character or hidden game designer, but also with that of the authors present with them in the game space. Wardrip-Fruin et al. (2009) propose a helpful redefinition of agency addressing some of these game/player conflicts. He argues that we should not consider player agency as a structural game property with the aim of "do anything", but instead as an interaction where the dramatic possibilities suggested by the world fit the player actions that the game supports. Karen and Theresa Tanenbaum argue in the same vein that in game spaces where narrative understanding is prioritised, agency can better be understood as the player's commitment to meaning (Tanenbaum \& Tanenbaum 2009). This view of agency prioritises communicative commitments between player and author, considering the game space as a stage for the improvised performance between author and player together (Tanenbaum \& Tanenbaum 2010); it is through this lens which I examine how it is that autobiographical games such as MEC:R evoke the particular desires that they satisfy, through both action and behaviour.

\section{Reading for player position}

Player positioning is considered within this paper as the perspective and contexts through which the player may interact with the game world and form their own interpretations of its autobiographical content. The player position informs the player how they are situated regarding the autobiography of the game: their position relative to the author, built from their contextual and sensory understanding of the scene. Player positioning need not be tied to a character or an avatar, then-a particularly useful concept for autobiographical games, where the author's presence pervades the game object as a whole. Authors in this autobiographical realm of game design can knowingly or unknowingly utilise levels of control or aesthetic/narrative abstraction-such as the possible interactions or the visual representations of the player character - to create barriers or intimacy, distance, or detail. Traditional concepts of "action"-based agency may be mitigated through positioning, which renegotiates the terms of shared persona and narrative agency; in other words, allowing the player to function and have purpose within the established boundaries and contexts of the experience.

By forgoing casting the player as an author character, autobiographical game authors may create spaces to share vulnerable lived experiences, without the player controlling the author's agency or claiming those personal experiences as their own. Instead, I consider playerauthor persona collaborations in varying ratios between three points of reference:

- player as protagonist, experiencing the game space under the author's influences, but through the player's own actions and contexts; 
- player as protagonist-proxy, behaving as a stand-in for the author, acting with their direction and contexts; or

- player as witness to the experience, given access to the author's thoughts, actions, or memories as a bystander.

Through these near-author positions, players may have meaningful, intimate access to thoughts, feelings, and memories, and act out their part from wherever they may best be positioned to understand what is being shared with them. In the case of $M E C: R$, narratively speaking the voice of the game is consistently that of Camilleri himself. However, the access I as the player am provided is a kaleidoscope of viewpoints and controls, as my positioning is readjusted scene by scene. MEC:R plays with this notion of self throughout, asking the player to adapt to a changing, fluid player position as the game progresses. While MEC:R assures me that my play will reveal Camilleri to me, it does not tell me I will be him, and I am not encouraged to strive to do so as I play. Addressing the protagonist, protagonist-proxy, and witness positions, in turn, I will examine how MEC:R repositions players within each game track to support affective and cognitive connection with the shared author/player persona.

\section{Negotiated Persona Through Player Position}

\section{Player as protagonist}

Although the term "protagonist" generally refers to a character central to a narrative (Miller 2004, pp. 89-105), in the case of player positioning, I consider the "player as protagonist" to mean that it is the player who is the focus of their own attention within the scene. Rather than having the player act as though they are the author, they are instead given primary control over the scene and asked to find meaning in their actions and responses. Assuming a protagonist position presents an immediacy of the connection between the player and the game space-one where the player is given the opportunity to play directly in the space, inhabiting, and acting within the scene primarily as themself. The idea of the player performing as the author may be stated or implied in the game's fiction or meta-text. If the player is provided with an avatar in an autobiographical game, it may be an obvious representation of the author, and not presented as a blank slate for the player's projections. Arguably, though, where the player is presented a scene as a 'real-time' event (a reaction-based game, for example), or focused internally on their own presence and body, the requirement of piloting or inhabiting a character may be a cognitive one less demanding than the affective responses arising from the player's own experience.

When players are asked to make meaning from their surroundings largely through their actions, and where affective choices take precedence over deliberate cognitive choices, authorplayer understanding lies in the internal, self-focused interpretations of events. The author may direct play through the allowances of the scene and the options provided, but the player utilises their body outside of the game extensively. They are "double- situated" as a game entity, their interactions with the hardware and software re-embodied in the game as it responds to their input, establishing a shared phenomenological physicality with the author (Ensslin 2009). I may, for example, find shared frustrations or physical responses with the author as I try to adequately control my on-screen presence, blurring the separation of my in- and out-of-game self. By making the task an extended, complex act of play rather than a single button to carry out my intention (press $X$ to pick up an object, or click to open a door), the conditions of play become more active and involved and so I may become more aware and more insightful through my active participation in the task. Regardless of whether the interaction is relaxed or high tension, when the act itself is part of the narrative and the execution of the mechanic is core to finding 
meaning in the scene, the player may benefit from being given more front-seat control over their behaviour. The player as protagonist positioning, then, in allowing players high degrees of controllable action, lends itself in autobiographical spaces to the experience of instinctive motivations, bodily actions, and spaces where the player's immediate responses take priority. $M E C: R$ most often asks me to step in and play without context when the matter at hand is rooted in bodily experiences, and a great deal of my play prioritises awareness of bodily presence, sensations, and reactions. In the first interaction of the game, after its title sequence, the player drags the needle of a record player onto the image of a record which serves as the game's title screen. This action takes place before any idea of being a character is introduced. This is crucial to the player as protagonist position as arguably the first act the player undertakes in the game is as themself. These types of largely wordless moments of physically-focused interaction ask me to find meaning, not in cognitive understanding of the complex emotional history of Camilleri, but in the shared experience of physicality: an understanding of his life rooted in my embodied responses, different though those may inevitably be.

Where Camilleri's anecdotes of play focus around the feeling of a generic task rather than a specific memorable moment-a complex hand-eye coordination challenge frequently set to him by an aunt, or the pitfalls of clumsy everyday interactions carried out in a second language-I am let loose to understand these experiences through my own abilities and reactions. The meaning that takes precedence is the immediate frustration, embarrassment, and attention elicited by the event and by the success or failure of the action. In autobiographical games, though the hands I manipulate on the screen or the eyes I gaze out from may nominally be the author's, I am asked here to commit my attention, my focus, and my physicality differently than a digital game would otherwise demand of a task, such as picking up an object or shaking a hand. The quick-time style events presented in the game track Oranje focus the player on the impulsive responses and perceived need for haste that arises when they are surprised by others. The frantic actions in play require quick reaction times, and a speed read of the situationwhether timing a button press to choose the right option between a handshake or a fist-bump, or desperately figuring out the correct response to a cashier before passing the socially acceptable time to answer. No access is provided to the author's context for the scene, nor any narrative goal required of me, and so I cannot act in the author's stead-I act as myself, due to the constraints that extend a mechanic rooted in sharing a feeling. The lack of information, the cold opening, and the mere moments to react-all may invoke a flustered state much akin to an unexpected social awkwardness, and so are as much a part of understanding the interaction as the actual act of timing the move correctly. By amalgamating the individual experiences into one representative task, and then placing that interaction into the player's own hands both on and off-screen, Camilleri invites players to know him only by their personal understanding and responses.

We see this same use of task-orientated presence in Indelible (2015) by Melody Lee (Zhi Xin), a game comprising three short vignettes about dealing with an unexpected period in public. Built around this shared social-body experience, rather than a specific memory from a specific person's life, Indelible strips background, foreshadowing, or context completely: the game simply throws players straight into the action of the first game-rushing to a public bathroom, attempting to cover a visible blood stain-and assumes the player has some context and knowledge to ground the experience. By being in direct control of my responses, I am asked to confront the shame or embarrassment bodily functions can bring. In the second vignette, players struggle to correctly position and insert a tampon, the difficulty is exaggerated by an unpredictability of movement in relation to the mouse input. Though I see 'my' body as an onlooker, through a side-on view of abstract line art, the frustrations of the moment and battles with my physical existence are conveyed through my bodily connection to the mechanic. In the 
third game, players try to clean blood stains from underwear, repositioning them under the water with the mouse in one hand and mashing buttons to scrub with the other. The lack of visible hands on-screen does not inhibit my connection to the shame this body brought me, or the unfairness of this moment.

That a lack of physical/visual form should not inhibit protagonist positioning suggests inserting ourselves as an immediate presence is not as simple as hopping into a waiting vessel. Indeed, throughout $M E C: R$, my bodily sense of presence takes many varied forms. I may be a pair of hands or even just the one, or my physical existence may be merely implied. The game track Silippo is formatted entirely in the style of a text adventure or interactive narrative, but it is crafted such that player access to the narrative it tells is immediate and close. In this track, which I also argue is MEC:R's most traditionally narrative moment, we are told a bedtime story. My body is missing entirely from the scene (I see only white text on a black background), yet I still find myself receiving bodily information as I listen to the tale. My body becomes a known presence through the aesthetic presentation of the scene, if not a visible one; as the tale continues, the text visually blurs and fades, its content becoming less coherent. Looking at the scene on the screen, my eyes can understand a bodily response through the altered text-I am becoming unfocused on the voice that speaks to me, not 'hearing' as clearly as before; perhaps I am falling asleep. Though I see only the text, I am provided poetic feedback to shape a bodily experience.

This bodily awareness may come from a specific recreation of an internal system or provide the context to a whole scene; although it may be difficult to recreate senses beyond sight and sound, the player can at least perceive the entirety of a situation to better grasp what those senses may have told them. Even with a body on screen, extracted to a distant viewpoint to better understand the situation, I may watch my body from afar but still be present in the scene in a very immediate sense. When my locus of bodily control is far removed-watching myself wander a beach from above as in the game track S.S.S, for example-despite my displacement from the body I am provided, I may feel this presence is still my own. Players are given no task to complete in S.S.S, no guidance on where to go, no time limit or suggestions; the scene allows me to enjoy it however I choose. With the author's influence over my actions not noticeably present in the scene, and nothing to understand but the sensation of a day at the beach, there is no cognitive demand to comprehend another's specific motives. Though I am far from my avatar, I am present wholly in the scene, without any obvious detachment.

In Indelible's opening moments, I find this same duality of visual separation yet affective closeness. Here, my relinquished control over the body as a whole serves to reinforce a different sensation to focus my attention; namely, that of panic. Almost on autopilot, my in-game entity, which I watch from above, navigates their way to the nearest restroom. Removed from an inner locus of control, I must watch this body, external from it, and see how it elicits the stares of strangers; I focus my physicality on hiding the stain I bear with a handbag, swinging my hands from side to side as I endeavour to conceal it from all angles. Back in MEC:R's bedtime tale vignette, my bodily autonomy is stripped down for a similar effect. The playable portion of the screen-my vision, from within myself-is reduced over time as I mumble responses. Eventually, my input to the tale is blurred out and illegible, just as the text becomes more nonsensical, as I struggle to stay awake and active in the storytelling. Like falling asleep, my slowly closing eyelids are not necessarily a voluntary function. Just as the uncontrolled path I hurry through in panic, I can understand what my involuntary closing eyes means; that my body is not always fully under my control. 


\section{Player as protagonist-proxy}

While positioning the player as the protagonist prompts players to examine their affective understanding of the game world (and the author's experience), positioning the player as protagonist-proxy asks them to examine their cognitive connection to the game instead. The player as a proxy for the author's actions and choices may take on a near-protagonist role, and be given some level of control over the scene but may remain distanced from the immediate emotional responses. They are, instead, focused on understanding their actions more contextually. Stepping away from the close self-focus of the protagonist, this positioning inserts a veneer of the author over my own in-game presence. I perform as or alongside the author who becomes spectatorial, directing and shadowing my actions as I act in tandem with them. In this sense, the protagonist-proxy position sees me to some extent as a puppet-player in the scene. My performances are shaped through the author's stage directions and contexts, the form I take in the space, the actions and choices that are available to me, and the reactions that the game world offers back. Players can step into more complex situations with their own intentions and interpretations, with any necessary contexts to the scene being provided by the author.

In a space between playing Camilleri's life and merely watching it, I find myself carrying out ghosts of his past conversations without the contexts that brought him to them. In Oranje, I greet party hosts nonsensically for reasons I do not understand (I, like many players, do not share the cultural knowledge of birthday traditions in the Netherlands). As I watch my game body and its reflection stare at each other in the mirror of Otoloop (a game track that loops endlessly unless skipped in the game's minimal interface), I fail to escape negative patterns of thought and behaviour, no matter what my intentions may be. I see a version of my player/author self carrying out tasks under my instruction, and am steered toward questioning and therefore understanding the narrative or personal meaning to my actions, rather than simply feeling my immediate affective responses. I am encouraged to consider the author's lens alongside my own frame of reference through my connection to the scene. I find myself closed off from the most intimate moments, and separated from being wholly in the scene, my in-game presence, and even the full emotional weight of context and consequence. In the track Øresund, my Camilleri counterpart talks to a faceless woman in a train station, the conversation moving forward facilitated by my choices. My stand-in avatar is unmoving, placed between the womanthe other party to the conversation - and my own position, observing the conversation externally. Facing away from me as we talk through the open doorway of a train, I stare at the back of my protagonist-proxy presence, the conduit through which I speak but a body I do not control. As I begin to unfold what this conversation is, and whom we are talking to, my conversation flickers through time; clothes change with each new attempt to connect to the woman, whole chunks of conversation appear to be missing. I am not acting out a conversation as myself, but investigating a number of previous conversations through small moments of Camilleri's memory. I am provided with a selection of sentences to choose from, which provides space for me to act how I believe Camillieri would or should have done. Although the responses from which I choose are presented to me in the exact way I will say them (rather than, say, the topic-based prompts of larger roleplaying games such as Mass Effect, or the emotional response systems seen in games such as L.A. Noire), my player positioning as an agent in the scene has me move away from a full protagonist role. I am positioned as an external entity, watching two other people talk from outside the body, and more importantly outside the conversation. The history behind it and the details of my author-self's reactions are inconsequential to my understanding of the conversation's tone. I cannot, at any point, even see my own face. A layer of emotional distance yawns between me, the player, and me the character-and even more so between me and the woman I am speaking with, and the reality of where the conversation has come from. I 
understand what these moments were, to Camilleri, through deciphering through his lens on one hand, and my own on the other.

However, this cognitive understanding between author and player does not necessarily imply a static in-game presence or rely on interactive fiction or written game narrative. In the track Laurana, after a brief opening message explaining that exams are approaching, players are in charge of a god-like, top-down management game as they pilot a white square (Camilleri, they can reasonably assume) around a noisy house. Managing to study becomes almost a puzzle, a balance of focus on the avatar and the game's information overlay - two aspects of bodily/cognitive awareness in the scene. With one eye I monitor the ever-decreasing time until my exam, and with the other I watch the increase in my knowledge bar, all while constantly redirecting the avatar under my control to flee the noises created by others. I am not inhabiting the house or the moment in a bodily sense, but instead attempting a strategic placing of my cube-self in the game map, while monitoring resources and the approaching threats. While this splintering of my attention may aptly recreate a stressful situation and invoke flustered, distracted responses, contextually I do not know whom I am avoiding, what I am studying, or why. What matters here is not what I would do when presented with all the facts, so much as that I can understand the frustrations Camilleri felt under these particular constraints. The fine detail does not, to the player, convey any extra meaning-and so does not, in the context of the scene, really matter. There is a distance between my actions and my complete understanding of them, similar to the dexterity games I play when positioned as the protagonist. Here, although, I am not asked to understand the motions I make or the affective frustrations of the task, but the complexity of the situation and the actions of the author. I study under the circumstances of Camilleri, using his own room-switching strategy, to understand the complicated balancing of expectations and external pressures; my full visual of the house plan, the context-setting of the opening screen text paragraphs and the interface progress bars all ask me to act with a narrative commitment to the author's experience. I amalgamate these experiences to approximate Camilleri's cognitive and bodily awarenesses, and I act according to his habits. My only alternative is to walk my cube out the door and leave.

By curating the experience of the player through a protagonist-proxy and therefore distanced position and providing only the salient details such as a conversation that frequently occurs at a train station goodbye or a house that is too loud to study, the player has just enough context to make meaning of the autobiographical feeling of the scene from their action in it. Positioning a player as a protagonist-proxy offers a distance between the author's potentially very personal lived experiences and the player's in-game actions, overlapping the two through the details that are key to whatever meaning the player is asked to explore. The tools to understand the author are the contexts within which I act, and the interactions illustrating what the author would, or did attempt. As an author proxy character, players may find their choices, actions or presence in the game world more directly influenced by the author's experiences or memories. Positioned with the author between myself and the moment the vignette explores, I negotiate my responses and desires through the filter of the author's presence. Where I aim to understand both the game scene and space and the motivations or responses of my avatar, I translate my actions through the contexts of the author's experience. To a certain extent, I am walking alongside the author in the scene-both of us on the same path, but with our experiences shaped by our personal context. The author-shaped version of the player as proxy comes with internal complications and restrictions placed to recreate, resemble, or reflect on the author's own lived experiences through my own interpretations of my play. Within the game my presence is a cast shadow, a poetic rather than literal translation of the author's lived experience, directed by their presence and the interactive possibilities they have provided. 


\section{Player as witness}

The player position as witness presents perhaps the most subversive mode of player positioning, stepping the furthest away from the widely-accepted notion in larger video game productions that a player should have a direct impact on or control of the game world around them-and that game worlds as objects exist around the player (as a character or avatar) at their narrative centre. Relying instead on the evocative aesthetic and narrative elements to give the player a sense of meaning, player as witness provides a great deal of control and protection over the portrayal of an author's lived experience, while still granting the player close and open access to the intimate moments being shared. By positioning a player as a witness to the events, memories, or feelings shown within the game, the game appears to offer a playful method of sharing without passing over control-allowing players access to lived experiences without placing them in the position of the author.

Positioned as witness, the player is, in a sense, almost removed from the game as an active agent, playing in the space of the story rather than as an active part of it. Where the player's role in the game is diverted away from solving, changing, or forming the narrative, they may instead focus on the delivery and experience as the ludic element of the game. In the space of the game, the player may explore the narrative simply by navigating through it. In doing so, the act of witnessing becomes just that: an action that the player is taking upon themselves, as themself, to understand the author. As such, we see that in its most intimate moments-namely, those dealing with ephemera of Camilleri's life in an unrepresented and literal form-MEC:R shifts the player into a passive role almost, although not entirely, disconnected from the play.

The opening and ending scenes of MEC:R (Pieces and Lei Disse) see me witnessing Camilleri through his personal ephemera: various small items laid before me on a desk. Although the 'thoughts' that appear on the screen when I click on an item are written in the first person ("I wonder if..."), it is hard to find anything that implies I am assuming the place of the author, or that this is my space. Although cognitively I may piece this together from my access to an intimate workspace and having thoughts on the objects available, the emotional connection to the objects on the table is not familiarity but curiosity. The musings triggered by the objects, small snippets without context, could easily be my own. However, as I have no memory of them and no context to explain them, I view them through my own eyes before viewing them through Camilleri's. Although my interactions may flick a light switch or turn a tablet on (confirming me as existing somehow in this digital room), I cannot otherwise alter the items before me, and I am asked to do nothing with them. It is the act of seeing that we have been brought here for, to understand an element of Camilleri's life through our witnessing; although he has no physical presence in the game space for this scene, the feeling is of listening to him talk to me as I point out one object, then the next.

However, positioning a player as a witness does not necessarily require the player's physical presence to be removed visually from the scene. In the same manner as wandering the empty halls of an exhibit, the player may well be located within a physical representation of memory and self, finding themselves in the first-person view and with a visible digital body, but distanced in some other way from the objects and narratives within. The interactive diary game, Sacramento (Dziff 2016) for example, is a first-person, 3D space, where the player is physically present in the game as a hand, brought to the player's line of sight on the screen when they check their watch. While the player has a bodily presence in the world, the game world responds very little to their passage, offering no interactions, text, or prompts to act. The game, made up of sketches created by the author, feels almost like a gallery visit where the player's presence is only for themselves. To explore the watercolour diaries Sacramento displays, players are placed 
bodily into a digital landscape built from the author's sketches, dropped off there quite literally at a train station, then left to explore. They can see the world shift and come to life as animations play when they approach each new feature, the world playfully reacting to the player rather than the other way around. Players are asked only to admire a world which acknowledges, but does not require, their presence.

Witness player positioning is exemplified in the genre of 'walking simulators', in which active play is centred around the slow uncovering, exploring, or deciphering of a game space rather than changing, achieving, or altering events (Koenitz 2017). There is a similar approach in interface games-games played via interacting with a simulated technology on the screen, uncovering information through unearthing digital ephemera. Clicking around the brightly coloured personal desktop of My Computer (Gibson 2017) or flicking through the projector slides depicting fading memories in Mushrooms Red As Meat (Godliman 2016), players aren't asked to do so with any particular purpose in mind. When I look through these digital artifacts, it is through examining and interpreting their content and aesthetics that I find my understanding of the author; my physicality in the game sense is largely unrequired.

\section{Player positions in parallel}

Although I have established three points of the positioning framework that define the player position in relation to the author, that is not to say that these three positions are discreet, disconnected, or mutually exclusive. For example, in and i made sure to hold your head sideways, a 2017 autobiographical game by Jenny Jiao Hsia, the player is plausibly positioned as both a protagonist and a witness simultaneously. The game is presented as an unchangeable linear narration (about waking up after a night out with missing memory), as a friend relays the events of the missing night. Fragments of text are delivered alongside deconstructed sketches of the author and others involved in the event. I have none of the author's contexts for this recollection-I do not know any of these people, or when it happened, or why-and so I follow along with events I was not part of as an onlooker or listener overhearing a conversation. To $\mathrm{read} /$ witness this event meaningfully, however, I perceive it through a protagonist-like element that gives a better understanding of the author's experience remembering and deciphering after the fact. My interactions with the game see me manipulate the scattered lines of these drawings, moving them around with the keys of my keyboard until a comprehensible image appears; an act not unlike trying to piece together a memory from fragmented, half-recalled sensations. I draw understanding of the tone of the experience through rough outlines of characters and places. In a way, I am the protagonist of the feeling of remembering, but a witness to the narrative, exploring two aspects of the author's experience from different positions at once.

\section{CONCLUSIONS}

Arguably one of the greatest challenges of autobiographical game works is establishing a selfnarrative that holds personal and player meaning, without surrendering the author's narrative and bodily agency to another-thereby rendering its status as autobiography somewhat inconsequential. While it may seem at odds with the intentions of autobiographical works to create them through shared acts of play, Camilleri's MEC:R highlights the identity-ambiguity of player positioning as an interesting solution for sharing the intricacies of ineffable personal experience not as objective fact, but as embodied and contextualised personal perspectives. I argue that the use of player positioning (and repositioning) reduces tensions between player and author as separate entities within the game space, and that this author-player shared identity makes room for players in experiences they may otherwise struggle to understand meaningfully. 
That is not to say that player positioning addresses all author-player-game tensions. This framework may be harder to incorporate into autobiographical games modelled more after traditional first-person, story-focused games, for example. It may also be important to remember that the player brings their personal context to the game space, and their own individual sense of their situated self. For example, what may, from the author's perspective (consciously or unconsciously), be very firmly a position of witnessing, could, to a player with adequate shared experiences, feel more like a protagonist positioning, an act they have a bodily connection to.

This examination of player positioning primarily explores how a game's aesthetics, contexts, and interactive/somatic experiences inform the perspective of the player and their closeness to the author. However, influences from the game's external framing-such as how the player is introduced to elements of the game and its meaning through the game pages and texts surrounding it—should not be ignored. Although a sense of self within game space may be heavily influenced by the way players see, hear, act, and understand within the game, they are not immune to the contexts of when, where, and how the game is encountered within the physical world.

$M E C: R$ demonstrates the potential power of an abstract, impermanent identity within personal narrative games; somewhere between lived, recreated, or observed life experiences, meaningful understanding arises. This positioning allows for an interpretive, nuanced understanding of Camilleri through various perspectives and proximities to and of the author, in the face of the self-driven and emergent meaning-making by the player, as a co-creator and performer. By asking the player to constantly renegotiate their cognitive and bodily relationship to the screen and the author, repositioning their locus of understanding, and rebalancing the weight of their doubly-situated self, we create intimate moments of shared experience and understanding. In this way, I believe that $M E C: R$ uses the fuzzy, interpretive notion of the self to obtain an intimate tone, through which the player is invited to understand another's experience without inhabiting it as an actor.

\section{WORKS CITED}

Apperley, TH \& Clemens, J 2017, 'Flipping out: Avatars and identity', in Boundaries of Self and Reality Online, Elsevier, pp. 41-56.

Barros, CA 1998, Autobiography: Narrative of transformation, University of Michigan Press.

Crick, T 2011, 'The game body: Toward a phenomenology of contemporary video gaming', Games and Culture, vol. 6, no. 3, pp. 259-269.

Barthes, R 1977 [1967], 'The Death of the Author', in Image, Music, Text, Translated by S. Heath. Fontana Press, London, pp. 142-148.

Camilleri, A 2016a, Memoir en Code: Reissue, videogame <https://www.memoirencode.com/>.

Camilleri, A 2016b, retrieved from <https://twitter.com/alexkalopsia/status/778641053683486721>.

Camileri, A 2016c, 'Memoir En Code Presskit', retrieved from <https://www.kalopsiagames.com/press/sheet.php?p=Memoir\%20En\%20Code\%20Rei ssue>.

Dziff 2016, Sacramento, videogame <https://dziff.itch.io/sacramento>.

Ensslin, A 2009, 'Respiratory narrative: Multimodality and cybernetic corporeality in "physiocybertext"', in New perspectives on narrative and multimodality, Routledge, pp. 169-179.

Hsia, J 2017, and i made sure to hold your head sideways, videogame <https://q_dork.itch.io/andi-made-sure-to-hold-your-head-sideways $>$.

Gibson, S 2017, My Computer, videogame <https://sgx.itch.io/my-computer>. 
Godliman, A 2016, Mushrooms Red As Meat, videogame $<$ https://acgodliman.itch.io/mushrooms-red-as-meat>.

Koenitz, H 2017, 'Beyond "Walking Simulators"-Games as the Narrative Avant-Garde'.

Lee, M 2015, Indelible, videogame <https://melodily.itch.io/indelible>

Merleau-Ponty, M. and Smith, C., 1962. Phenomenology of perception (Vol. 2012). Routledge, London.

Miller, CH 2004. Digital storytelling: a creator's guide to interactive entertainment, Elsevier/Focal Press, Amsterdam Boston

Roine, H-R 2015, 'How You Emerge from This Game Is Up to You: Agency, Positioning, and Narrativity in The Mass Effect Trilogy', in Narrative Theory, Literature, and New Media, Routledge, pp. 67-86.

Shaw, A 2011, “"He could be a bunny rabbit for all I care”: Exploring identification in digital games'.

Tanenbaum, K, Tanenbaum, T 2009, 'Commitment to Meaning: A Reframing of Agency in Games' Wardrip-Fruin, N, Mateas, M, Dow, S \& Sali, S 2009, 'Agency Reconsidered.'

Tanenbaum, K, Tanenbaum, T 2010. 'Agency as commitment to meaning: communicative competence in games', Digital Creativity, vol. 21, no. 1, pp. 11-17.

Waggoner, Z 2009, My Avatar, My Self: Identity in Video Role-Playing Games, McFarland, Incorporated, Publishers.

Werning, S 2017, "The persona in autobiographical game-making as a playful performance of the self', Persona Studies, vol. 3, no. 1, pp. 28-42.

Wilde, P 2018, 'Avatar affectivity and affection.', Transformations (14443775), no. 31.

Wood, H 2017, 'Dynamic Syuzhets: Writing and Design Methods for Playable Stories', in Springer, pp. 24-37.

Yee, N \& Bailenson, J 2007, 'The Proteus effect: The effect of transformed self- representation on behavior', Human communication research, vol. 33, no. 3, pp. 271-290. 